\title{
DAVID FOSTER WALLACE ON THE ROLE OF THE ESSAY IN THE WORLD OF TOTAL NOISE: “DECIDERIZATION 2007: A SPECIAL REPORT“
}

\author{
If an art form is marginalized it's because it's not speaking to people. \\ (David Foster Wallace, "Something Real American”, interview by Laura Miller) \\ You can call the pieces journalism and I think you should, and you can also call \\ them literary performances and I think that that's just as accurate. \\ (Colin Harrison, "Editors on Wallace", The David Foster Wallace \\ Symposium at Harry Ransom Center, 2012)
}

\begin{abstract}
The intention of this paper is to shed a slightly different light on the literary work of David Foster Wallace by focusing on his nonfictional writing, primarily on his introduction to The Best American Essays 2007, titled "Deciderization 2007 - a Special Report". In this short but condensed text Wallace both demonstrates his recognizably analytical literary voice and offers a number of original insights into how important the role of the essay is today. He detects some of the most prominent characteristics of contemporary Western society, dominated by "Total Noise" as he calls it, and in this context he sees the essay as a means of organizing such a chaotic reality. The paper also tries to argue that Wallace's nonfictional writing might offer a valuable perspective on his entire work.
\end{abstract}

Key words: David Foster Wallace, nonfiction, contemporary American essay, the role of the essay in the $21^{\text {st }}$ century

\section{Introduction: both fiction and not}

David Foster Wallace is known as an American writer in a non-trivial sense because of his deep interest and immersion in the American culture, society and literature (Burn 2012: xii). However redundant this statement might seem, it is especially noteworthy while (re)considering his nonfiction.

Nowhere did Wallace examine the larger cultural assumptions within each topic he wrote about with more directness and clarity than in his nonfiction. His concerns

${ }^{*}$ PhD candidate, Faculty of Philosophy, University of Novi Sad, Dr Zorana Đinđića 2, 21000 Novi Sad, Serbia; e-mail: spasictijana@gmail.com 
were numerous and ranged from the deeply intricate relationship between television and US fiction, the moral dilemma attached to eating lobsters for gustatory pleasure alone, to the unexpected sadness lying at the core of the American pornographic industry. His nonfiction has been said to have offered a new, more direct function than his fiction of "documenting the folly of American excess" (Severs 2018: 111) and to have opened a valuable perspective into Wallace's mind both as a writer and as a person.

Regardless of all the differences and divides on the two sides of his oeuvre, the trademarks of Wallace's writing style are easily traceable throughout his work, both fictional and not: the frequently gargantuan length, the unique humor, and the excessive use of footnotes to name a few. More importantly, it is possible to identify clear thematic threads running through his entire oeuvre, upon a closer examination of his nonfiction.

During Wallace's lifetime and after, the critical reception and scholarly research on Wallace's nonfictional work have been interestingly scarce ${ }^{1}$. As another barrier to a deep analysis and appreciation of the nonfictional segment of his work stands the fact that Wallace himself considered it to be less relevant. He expressed his conflicting feelings in his letter to Don DeLillo by saying: "I do not know why the comparative ease and pleasure of writing nonfiction always confirms my intuition that fiction is really What I'm Supposed to Do" (Max 2012: 260). This attitude might stem from the historical undermining of the essay as a genre ${ }^{2}$. What is much more likely to be the cause of such an attitude is Wallace's lifelong tendency to doubt the quality of his own writing ${ }^{3}$.

Within the scarce scholarly research of Wallace's nonfictional work there are two principal debates. One is rooted in the question of whether his nonfiction should be considered (post-)postmodernist or not (Severs 2018: 122) and the other delves deeper into the question of whether his nonfictional pieces belong to literary journalism to an extent or should simply be called essays (regardless of whether we are referring to reviews, reported journalism, or other pieces of writing) $)^{4}$. Perhaps the

\footnotetext{
${ }^{1}$ Josh Roiland seems to be one of the very few academic researchers who has dedicated significant effort to Wallace's nonfictional work; his new book, The Rest is Silence: The Unexplored Nonfiction of David Foster Wallace, is currently under review at Bloomsbury Press.

${ }^{2}$ Undermining the essay as genre is emphasised multiple times in Douglas Atkins's study of its historical development called Tracing the Essay: Through Experience to Truth.

${ }^{3} \mathrm{He}$ famously said that his first novel, The Broom of the System, could have been written by "a very smart 14 year old" (Max 2012: 48).

${ }^{4}$ Roiland goes so far as to claim that "it is nonetheless important to understand that Wallace wrote in the tradition of the literary journalist, because the form and its field of study provide a whole catalogue of approaches to understanding his stories in relation to his reviews, speeches, and essays" (Roiland 2012: 26).
} 
most accurate conclusion would be that essay has been "so heterogeneous as to escape easy definition" (Severs 2018: 122).

Wallace was well aware of these "taxonomic arguments" regarding nonfiction. By way of almost adding another layer to the complexity of genre classification within the realm of nonfiction, he famously said that "nobody here is quite sure how to classify the writing that results when novelists and poets write nonfiction for magazines" (Burn 2012: 154). In other words, not only is nonfiction as such prone to being (mis)classified, the matter becomes even more dubious when writers of fiction, such as himself, join the "other" side.

Although parsing the threads of this debate might be important, and it will be appropriately addressed in the paper, the purpose of suggesting a deeper view into Wallace's nonfiction is to find ways to thematically join it to the fictional part of his work, since it has been suggested that he approached most of his topics here without the "postmodernist pyrotechnics"s. It is noteworthy that nonfiction is where he developed many ideas that he used in his fiction. Wallace's best friend from college expressed this idea most clearly by saying that essays were the places where he "split his atoms".

One place where he exhibits a particularly important form of atom-splitting is his guest editor's introduction to Best American Essays 2007, a tiny text he openly hoped would escape the readers' radar, and therefore a place where he "hid" some of his greatest concerns regarding the American contemporary society and (his own) writing.

\section{Emergent truths}

In a 2003 interview with a fellow writer Dave Eggers, Wallace lamented that "there's no more complex, messy, community-wide argument (or 'dialogue'); political discourse is now a formulaic matter of preaching to one's own choir and demonizing the opposition". He ends his lament with a rhetorical question: "How can any of this possibly help me, the average citizen, deliberate about any number of complicated policy issues?" (Wallace 2012b: 74-75).

Wallace reiterates this idea in his essay "Deciderization 2007: A Special Report" by saying that "we, like diminished kings or rigidly insecure presidents, are reduced to being overwhelmed by info and interpretation, or else paralyzed by cynicism and anomie, or else - worst - seduced by some particular set of dogmatic talking-points" (Wallace 2012a: 316).

This essay belongs to the third thematic category of his nonfictional work. The first one is comprised of book reviews and aesthetic analyses which are scattered

\footnotetext{
${ }^{5}$ Michico Kakutani used this phrase in her appreciation of Wallace's work after his death (Roiland 2012: 50).

${ }^{6}$ Mark Costello at “Rereading David Foster Wallace," The New Yorker Festival 2012.
} 
throughout his three essay collections, the second one refers to accounts of consumer spectacle, largely concentrated in A Supposedly Fun Thing I'll Never Do Again, and the third is focused on the intersection of ethics and politics and it is primarily concentrated in the collections Consider the Lobster and Both Flesh and Not (Severs 2018: 112).

"Deciderization" is one of the last pieces of writing Wallace published in his lifetime, and it was re-published as one of the final essays in the posthumously published collection Both Flesh and Not. On this occasion, instead of being a "professional writer" for a brief moment he plays the role of a "professional reader" by being a guest editor for The Best American Essays 2007. Always a passionate collector of words, he deliberately uses for this title an incorrect one, with the intention of creating a pun on then-president George W. Bush's "penchant for verbal mishaps" (Roiland 2013: $156)^{7}$. Typically of Wallace's writing style, the message of the title is twofold: it not only openly expresses his criticism of the current political situation in the USA, but also immediately addresses the key thesis of his essay - the necessity of the reader's submission to decisions of various Deciders, be those presidents or anthology editors ${ }^{8}$.

With the exception of its length, this essay is reminiscent of the rest of Wallace's work in many ways. The underlying sadness found at unexpected places ("I find most memoirs sad in a way that I don't think their authors intend" (Wallace 2012a: 309)), burying most important insights in footnotes, which seem to have a life of their own but are also indispensable to the text, actively looking for ways to give the readers something valuable in return for their attention and effort, the effort which in the context of this essay he names "submission", and finally, our search for passive consumerist pleasure wherever possible ("the for-profit media is exquisitely attuned to the amount of detail we'll sit still for" (Wallace 2012a: 314)), to name just a few. By comprising many thematic threads which underpin his entire (nonfictional) work, "Deciderization" becomes one of the clearest articulations of ideas that guided his writing and life, much like his famous speech "This is Water" (Roiland 2012: 25).

Even though it has been largely overlooked by his readers to this day, "Deciderization" is in fact another proof of Wallace's unique talent for observation and his ability to turn into an "enormous floating eyeball" which is able to detect even the smallest details and report them back to the reader, only interpreted from a completely unexpected perspective.

\footnotetext{
${ }^{7}$ President Bush used the word decider in one of his press conferences in 2006 where he explicitly said: "I hear the voices, and I read the front page, and I know the speculation, but I am the decider and I decide what is best" (my emphasis).

${ }^{8}$ Another instance where he exhibited an even greater talent for compressing the entire plot in the title is definitely Infinite Jest, which alludes to at least two parallel pursuits of the novel: the inner plot containing the search for a video tape of a lethally entertaining, eponymous movie and the fact that American society, as Wallace sees it, expects of entertainment to be endless in the first place.
} 
In the recognizable manner in which he wrote his nonfiction, Wallace "slices his head open for us" (Wallace 2012b: 43) and takes us along for the ride on his musings, this time about the meaning and value of essay as genre. He manages to find an important connection between its value and what it means to be an educated and well-informed citizen of the $21^{\text {st }}$ century and colloquially names this connection "service essay". Apart from recognizing service to the reader as one of the fundamental principles of (his) writing, it is important here to notice "a subliminal connection to "the Service,"” as accountants in his posthumously published novel Pale King often call the IRS (Internal Revenue Service) (Severs 2018: 119). In Wallace's eyes, the IRS becomes one of the largest information-sifting systems, which makes it a system effectively able to deal with an aspect of contemporary life he was always fascinated by. Bearing in mind his lifelong obsession with information overwhelm and our capacity to handle it, it is no wonder that to Wallace, the best "service essays" are the ones which are "clear without being simplistic, comprehensive without being overwhelming, and critical without being shrill" (Wallace 2012a: 315). They are informative in both senses of the word: because they are offering organized information while being instructive at the same time.

As stated earlier, another pursuit he takes in this essay is the validation of essay as genre. If we exclude his numerous interviews, which have become an indispensable segment of his oeuvre, there is no other piece of nonfiction where he openly discusses essay as genre, neither formally, nor in terms of its cultural or literary value. Being an active participant in selecting the essays for The Best American Essays 2007 seems to have created a logical context for him to tackle this particular problem and put it in front of his readers. But despite being commander-in-chief of the anthology's selections, he openly admits that he "isn't sure what an essay even is, not that this is unusual" and supports his confession by claiming that he would, for example, enjoy the collection's first story regardless of its categorization (Wallace 2012a: 300, my emphasis). By doing this, Wallace is again creating an impression that his view about genres in general was "complex, multifaceted, and it evolved during his writing life" because he expressed contradictory claims in his interviews whenever he was asked about his own essays and newspaper articles (Roiland 2013: 156).

In "Deciderization", he founds this claim on the obvious fact that essay as a term has become "too broad to really signify" and is very different "from the sort of thing that Montaigne and Chesterton were doing when the essay was being codified" (Wallace 2012a: 301). The way Wallace resolves this complexity is by relying on his "gut certainty", but just like we all do, he wonders if it should be enough. At the end of this discussion he says that he generally prefers the term "literary nonfiction", which seems to even further complicate matters for researchers 9 .

\footnotetext{
${ }^{9}$ Roiland emphasizes Wallace's contradictory claims regarding genres throughout his research of Wallace's nonfictional work.
} 
Furthermore, "Deciderization" is perhaps the only place where Wallace openly stated that he is "not really even all that confident or concerned about the differences between nonfiction and fiction, with 'differences' here meaning formal or definitive" (Wallace 2012a: 301). When he talks about the differences between the two from the point of view of a writer, he does so by famously describing them as walking over two different types of abysses:

[A]ctually, so wait: the truth is that both fiction and non-fiction are scary; both feel like they're executed on tightropes, over abysses - it's the abysses that are different. Fiction's abyss is silence, nada. Whereas nonfiction's abyss is Total Noise, the seething static of every particular thing and experience, and one's total freedom of infinite choice about what to choose to attend to and represent and connect, and how, and why, etc. (Wallace 2012a: 302, my emphasis)

In much of his work, he alludes to Information Theory, by almost explaining the complexity of contemporary reality to himself and says a Decider is "simply" supposed to be a kind of an "entropy-reducing info processor" who is able to most effectively perform this task by the act of eliminating and/or deleting (Wallace 2012a: 304). He was very familiar with this task, and at one point he commented his experience as a journalist as having "received 500,000 discrete bits of information today, of which maybe twenty-five are important" (Burn 2012: 161). However we choose to describe the Decider's task, we all are increasingly dependent on this type of service, since "the quantity of available information [...] expands at roughly the rate of Moore's Law" (Wallace 2012a: 304). From this point of view, "Deciderization" is another testament to Wallace's increasing interest in theories of human information processing and neuroscience and of a new mode of epistemic humility he adopted towards the end of his life (Severs 2018: 112). He expresses his epistemic humility using his wellknown humor and sincerity and says at the end of the essay: "In sum, to really try to be informed and literate today is to feel stupid nearly all the time, and to need help" (Wallace 2012a: 317).

In other words, once again, but using a more direct language and "maximum tact" (Wallace 2012a: 308), he focuses closely on an obvious but rarely so intelligently discussed fact that contemporary culture has become too vast to even absorb individually, let alone try to make sense of or organize in any meaningful way. In Wallace's view, this exact ability used to be expected of any adult citizen who is both educated and well-informed, but it clearly is no longer conceivable. Therefore he believes we all need the type of essays he selected for the anthology because they are all very good at handling the contemporary world's complexity. 
According to Wallace, this is the primary value based on which he selected the particular essays to be a part of the anthology. All of them managed to "handle and respond to the tsunami of available fact, context, and perspective that constitutes Total Noise" and to do so in such a way that they do not simply add to the existing noise, but are "a vector of meaning" (Wallace 2012a: 312). It's about whether they are handling "sets of facts $[\ldots]$ in meaningful ways - ways that yield and illuminate truth instead of just adding more noise to the overall roar" (ibid.). And to him, noise is any piece of information which is redundant for the people who share the writer's opinion, and completely irrelevant to the ones who do not.

Being forced to "subcontract, outsource and submit to various other Deciders" (Wallace 2012a: 305) all the time is important to Wallace since it is threatening to our sense of ourselves as intelligent and free agents. And there is also a sub-context to his anxiety regarding submission to various Deciders: if he is hardly able to explain his own criteria based on which he made the final choices as to which pieces would be included in the anthology, then it must apply to all Deciders' criteria anywhere. In other words, most of the criteria are hard to explain and arbitrary to a frightening extent. Or at least they are heavily biased, which, as it turns out, seems to be a word producing additional anxiety to not only Wallace, but to the entire Western world as he sees it. But regardless of this, he is trying to define his own "exclusionary criteria" as thoroughly as possible. And he says he will do it combining "candor with maximum tact", which is a proof of his changing both personally and as a writer. His intention is to offer tangible reasons for making certain choices and also to give something back to the reader of whom so much submission is expected. And since the outsourcing seems to have no apparent alternative, Wallace's immediate conclusion is that perhaps our ability to choose our Deciders wisely has become "a measure of informed adulthood" (ibid.) This conclusion is invaluable for essay as a genre since it re-evaluates its position in the social, cultural and literary context of $21^{\text {st }}$-century America.

Ultimately, Wallace is once again focused on what he considered to be the most important in all writing, including his own: the ethical implications of the imbalance between the information overload surrounding us and our capacity or even willingness to give it our attention. To him, a lack of consciousness has larger ramifications than just feeling lost or confused. Refusing or failing to fully understand and interact with the complex reality to him means to avoid a moral responsibility, which he considered to be highly detrimental to us as human beings and also as active members of any society.

Connected to this is his conviction that essay's value also lies in its ability to address the current emergencies in the culture. He vividly supports this claim by describing current state in US culture as "a state of three-alarm emergency" and he believed such an emergency would not have happened if people "had been paying 
attention and handling information in a competent grown-up way" (Wallace 2012a: 313). What he realized in this essay and expressed so openly is typical of his work: that there are many more dimensions to mindful living, especially in a precarious democracy (Severs 2018: 119). Indulging in escapism - which is an underlying thematic thread of most of his work, Infinite Jest especially - is a dangerous proposition to him. Judging by his nonfiction in particular, unconsciousness leads to groupthink, gluttony, and selfdelusion. But excessive consciousness is equally unhealthy and dangerous, which he also addressed throughout his work ${ }^{10}$. Consequently, it can be said that Wallace's entire writing fluctuates inside the tension between overloading one's consciousness and the urge to surrender to oblivion. Furthermore, a large portion of his personal struggle also resided inside this tension.

The final inner connection Wallace draws between this essay and his previous work lies in the fact that in it he revisits some of the essential ideas from his Kenyon commencement speech, "This is Water". From "Deciderization" it is clear that Wallace believed that the newspaper stories or essays which managed to deliver the type of service he is talking about in this essay actually help readers live the type of conscious life that he advocated in his Kenyon speech (Roiland 2012: 27). This aids the service essay and is the destination of Wallace's career-long search for a viable form of postmodern moral values (Severs 2018: 120).

\section{Conclusion}

At the end of "Deciderization", Wallace called the stories he selected for the collection "models - not templates, but models — of ways I wish I could think and live in what seems to me this world" (Wallace 2012a: 317). He seems to have reached a conclusion which opens a new trajectory for the development of essay as genre in the $21^{\text {st }}$ century: if the original essays served Montaigne as guides through the mazes of his personal life, for Wallace they are here to guide us through the outer world.

And not only can essays as such serve the populace by acting as effective and conscientious filters of the overwhelming contemporary reality, but it also seems that Wallace's essays prove to be valuable guidelines into his complex fictional work. During his writing career and life, he managed to walk both tightropes over both types of abysses, showing an unprecedented skill and persistence, leaving us with one possible conclusion: that the only difference between his fiction and nonfiction is the formal one. While his novels and short stories mirror the reality he felt he was living in, trying to absorb it, word by word and come at the reader like an ocean, his essays

\footnotetext{
${ }^{10}$ For a deeper analysis of this topic, see J. Roiland: "Getting Away from it All: The Literary Journalism of David Foster Wallace and Nietzsche's Concept of Oblivion"; it is also worth noting that Wallace published a short story collection titled Oblivion in 2004.
} 
are a testament to his efforts to serve the same world in smaller, digestible portions. Everything we are expected to feel and live through while reading his fiction, we can process intellectually and discuss with him while reading his nonfiction.

Perhaps it is in his nonfiction where Wallace managed to find the new ways of writing he was looking for all his life in his fiction: essays, especially the ones he admires in "Deciderization", are the opposite of solipsistic, they are actively communicating with the reader instead of striking poses in narcissistic self-absorption and ultimately, they leave no room for the corrosive postmodernist irony he battled with as a writer. Maybe it is even possible to go as far as to claim that in essays, both the ones he wrote and the ones he considered to be the best examples of this underestimated and never fully defined genre, the author is able to show the naiveté and sincerity Wallace had hoped would have the courage for all his writing life.

\section{References}

Atkins, G. D. (2005). Tracing the Essay: Through Experience to Truth. Athens and London: University of Georgia Press.

Burn, S. J. (ed.) (2012). Conversations with David Foster Wallace. Jackson, Mississippi: University Press of Mississippi.

Editors on Wallace. (2012). The David Foster Wallace Symposium. The Harry Ransom Center at the University of Austin, Texas. (23 September 2019) <https://www. youtube.com/watch? $\mathrm{v}=$ IAfuZRryjHk\&t $=3 \mathrm{~s}>$.

Max, D. T. (2012). Every Love Story Is a Ghost Story: A Life of David Foster Wallace. New York: Viking.

Roiland, J. (2012). Getting Away from It All: The Literary Journalism of David Foster Wallace and Nietzsche's Concept of Oblivion. In: S. Cohen and L. Konstantinou (eds.), The Legacy of David Foster Wallace, Iowa City: University of Iowa Press, 25-52.

Roiland, J. (2013). The Fine Print: Uncovering the True Story of David Foster Wallace and the "Reality Boundary". Literary Journalism Studies, 5(2), 148-161.

Rereading David Foster Wallace. (2012). The New Yorker Festival. The New Yorker. (13 February 2019) <https://www.youtube.com/watch?v=JqN52yKI4pg\&t=11s $>$.

Severs, J. (2018). Wallace's Nonfiction. In: R. Clare (ed.), The Cambridge Companion to David Foster Wallace, Cambridge: Cambridge University Press, 111-124.

Wallace, D. F. (2012a). Both Flesh and Not. New York, Boston and London: Little, Brown and Company.

Wallace, D. F. (2012b). The Last Interview and Other Conversations. New York: Melville House Publishing. 